Cochrane Database of Systematic Reviews

\title{
Endoscopic mucosal resection for early gastric cancer (Review)
}

Bennett C, Wang Y, Pan T

Bennett C, Wang Y, Pan T.

Endoscopic mucosal resection for early gastric cancer.

Cochrane Database of Systematic Reviews 2009, Issue 4. Art. No.: CD004276.

DOI: 10.1002/14651858.CD004276.pub3.

www.cochranelibrary.com 
TABLE OF CONTENTS

HEADER 1

ABSTRACT

PLAIN LANGUAGE SUMMARY

BACKGROUND

OBJECTIVES

METHODS

RESULTS

DISCUSSION

AUTHORS' CONCLUSIONS

ACKNOWLEDGEMENTS

REFERENCES

CHARACTERISTICS OF STUDIES

APPENDICES

WHAT'S NEW

HISTORY

CONTRIBUTIONS OF AUTHORS

DECLARATIONS OF INTEREST

SOURCES OF SUPPORT

INDEX TERMS 
[Intervention Review]

\section{Endoscopic mucosal resection for early gastric cancer}

Cathy Bennett ${ }^{1}$, Yiping Wang 2 , Tao Pan ${ }^{2}$

1Systematic Research Ltd., Leicester, UK. 2Department of Gastroenterology, West China Hospital, Sichuan University, Chengdu, China

Contact address: Cathy Bennett, Systematic Research Ltd., Leicester, Leicestershire, UK. info@systematicresearch.co.uk, info@systematicresearch.co.uk.

Editorial group: Cochrane Upper GI and Pancreatic Diseases Group.

Publication status and date: Stable (no update expected for reasons given in 'What's new'), published in Issue 10, 2014.

Citation: Bennett C, Wang Y, Pan T. Endoscopic mucosal resection for early gastric cancer. Cochrane Database of Systematic Reviews 2009, Issue 4. Art. No.: CD004276. DOI: 10.1002/14651858.CD004276.pub3.

Copyright $(2014$ The Cochrane Collaboration. Published by John Wiley \& Sons, Ltd.

\section{A B S T R A C T}

\section{Background}

The treatment of early gastric cancer (EGC) using endoscopy, namely endoscopic mucosal resection (EMR), has been adopted for about 20 years, but the effectiveness and safety of the modality are still controversial. Furthermore, the risk of bias of trials of this technique has not been assessed systematically.

\section{Objectives}

The purpose of this review was to compare the effectiveness and safety of endoscopic mucosal resection with gastrectomy for the treatment of early gastric cancer.

\section{Search methods}

Searches were conducted on the Cochrane Central Register of Controlled Trials (CENTRAL) which includes the Cochrane Upper Gastrointestinal and Pancreatic Diseases Group (UGPD) Trials Register (The Cochrane Library 2005, Issue 1), MEDLINE (1966 to March 2005), EMBASE (1980 to March 2005), CINAHL (1985 to March 2005) and CBM (Chinese BioMedical Database 1982 to 2002). The searches of CENTRAL, MEDLINE and EMBASE were updated in February 2006, January 2009 and January 2011. Reference lists from trials selected by electronic searching were handsearched to identify further relevant trials. Published abstracts from conference proceedings from the United European Gastroenterology Week (published in Gut) and Digestive Disease Week (published in Gastroenterology) were handsearched. Members of the Cochrane UGPD Group, and experts in the field were contacted and asked to provide details of outstanding clinical trials and any relevant unpublished materials.

\section{Selection criteria}

All randomised controlled trials of early gastric cancer patients involving a treatment arm of EMR and a comparison arm of gastrectomy were to be included, but no RCTs were found.

\section{Data collection and analysis}

The review authors independently assessed the eligibility of potential trials and extracted the data.

\section{Main results}

There were no randomised controlled trials identified for systematic review. Available evidence derived from non-randomised controlled trials is discussed in the main text of this review. 


\section{Authors' conclusions}

There is a lack of randomised controlled trials in which endoscopic mucosal resection (EMR) is compared with gastrectomy for early gastric cancer. There is, therefore, a need for well-designed randomised controlled trials to determine the effects of EMR compared to gastrectomy.

\section{PLAIN LANGUAGE SUMMARY}

\section{Endoscopic mucosal resection for early stomach cancer}

There is a lack of randomised controlled trials (RCTs) in which endoscopic mucosal resection (EMR) is compared with surgery for early stomach cancer. There is a need for well-designed randomised controlled trials to determine the effects of EMR compared to gastrectomy. 


\section{B A C K G R O U N D}

\section{Description of the condition}

Stomach cancer is the fourth most common cancer worldwide. In the UK, it is the eighth most common cancer in males in the UK and thirteenth in females (Cancer Research UK). It is the second most common cause of death from cancer worldwide. Geographically, there are some high risk areas, such as Eastern Asia (China, Japan, Republic of Korea, Democratic Republic of Korea and Mongolia), and lower rates of occurrence in North America, Australia and New Zealand (Parkin 2002). The lowest rates are found in Western and Northern Africa (Cancer Research UK 2007). Early gastric cancer (EGC) was defined in 1962 by the Japanese Research Society for Gastric Cancer as tumours with invasion limited to the mucosa or submucosa of the stomach irrespective of lymph node involvement (Kojima 1998).

\section{Description of the intervention}

Surgical gastrectomy was the only method of treatment for EGC before endoscopic mucosal resection (EMR) or endoscopic mucosectomy was introduced in Japan (Hiki 1996). However, accumulated histopathological data on surgical gastric cancer specimens have revealed that many early gastric cancer patients did not have any metastatic lesions (Gotoda 2000; Tada 2000). That is, gastrectomy for resection of regional lymph nodes is not always required and the option of treating EGC using endoscopy, namely endoscopic mucosal resection (EMR), can be considered when the probability of lymph node metastasis is low.

The indications for EMR according to the Japanese Gastric Cancer Association Guidelines (Japanese GCA 1998; Eguchi 2003) include:

1. a tumour with a low risk of lymph node metastasis;

2. differentiated adenocarcinoma, intramucosal cancer;

3. a tumour of less than $20 \mathrm{~mm}$ in size, regardless of macroscopic type, and without ulcer findings.

\section{How the intervention might work}

EMR has the advantage of not only allowing the lesion to be examined histologically to reveal its extent and infiltration depth but also the outcome of treatment can be evaluated on the basis of macroscopic and histological findings. Therefore, EMR provides significant benefits for an accurate final diagnosis and eradication of submucosal lesions. The procedure is less invasive than surgical gastrectomy without sacrificing the possibility of a cure (Hiki 1996; Ono 2001). Because of this, EMR appears to be a good therapeutic modality for EGC, especially in patients at high risk of having severe complications or refusing surgery (Hamada 1996). Endoscopic treatment has become increasingly popular in recent years as an alternative to surgical treatment and with the hope of offering superior quality of life for the patient. EMR is considerably cheaper compared with conventional surgery (O'Mahony 2001). A low incidence of post-operative complaints and no severe complications have been reported (Takeshita 1997a; Suzuki 1999). No deaths related to complications of EMR were registered in a review of 1832 patients treated with EMR in Japan over 10 years (Kojima 1998). Due to technological advances in detection methods, almost 10,000 cases of early gastric cancer are diagnosed every year in Japan, corresponding to $40 \%$ to $50 \%$ of all gastric cancers (Kojima 1998). The five-year survival rate of patients with
EGC in that country is about $90 \%$ after gastrectomy and complete removal of primary and secondary lymph nodes (Ono 2001). Five and 10-year survival rates of EMR are similar to conventional surgery (Tada 2000). Thus, in differentiated gastric adenocarcinoma with minimal submucosal invasion and not accompanied by peptic ulcer or other risk factors, such as lymphatic invasion EMR alone may have a curative potential, without the necessity for further radical surgery (Kashimura 1999; Tada 2000).

\section{Why it is important to do this review}

Because of the excellent results of EMR, experts believe that early detection of cancerous lesions and their treatment using EMR is the ideal goal of cancer treatment in people with cancers of the gastrointestinal tract (Ono 2001; Inoue 2002). EMR for mucosal gastric carcinoma without lymph node metastasis is the currently accepted curative procedure in Japan. Many other countries have adopted EMR treatment for EGC, such as China, the Americas and Western countries (Zhou 1995; Giovannini 1999; Llorens 2000; Wehrmann 2001; Ahmad 2002).

There are numerous techniques and many published studies evaluating EMR available (Zhou 1995; Kajiyama 1996; Takeshita 1997b; Giovannini 1999; Suzuki 1999; Kim 2000; Wehrmann 2001; Yoshikane 2001; Ahmad 2002). However, the quality of these trials has not been assessed systematically even though the technique of EMR has been in use for about 20 years.

\section{O B JECT IVES}

The purpose of this review was to compare the effectiveness and the safety of EMR with gastrectomy for the treatment of EGC.

\section{METHODS}

\section{Criteria for considering studies for this review Types of studies}

We searched for all randomised and quasi-randomised controlled trials of EGC patients involving a treatment arm of EMR and a comparison arm of gastrectomy. Abstracts or unpublished articles were included.

\section{Types of participants}

Participants included patients with EGC defined as tumours with invasion limited to the intermucosa and submucosa, using the Japan or Vienna Criteria (Schlemper 2000; Eguchi 2003), as these types of lesions have a low risk of metastasis (Yamao 1996).

\section{Types of interventions}

Endoscopic mucosal resection (EMR) was compared with gastrectomy (including partial, distal and total gastrectomy) in the treatment of EGC.

\section{Types of outcome measures}

\section{Primary outcomes}

Five-year survival rate.

\section{Secondary outcomes}

- Recurrence.

- Metastasis after therapy. 
- Failure cases of EMR (patients whose EGC is not resected by EMR).

- Reports of complications, including bleeding, perforation and death associated with EMR.

- Quality of life measures.

Cost assessments were not performed.

\section{Search methods for identification of studies}

\section{Electronic searches}

Searches were conducted on the Cochrane Central Register of Controlled Trials (CENTRAL) which includes the Cochrane Upper Gastrointestinal and Pancreatic Diseases Group (UGPD) Trials Register (The Cochrane Library 2005, Issue 1), MEDLINE (1966 to March 2005), EMBASE (1980 to March 2005), CINAHL (1985 to March 2005) and CBM (Chinese BioMedical Database 1982 to 2002). The searches of CENTRAL, MEDLINE and EMBASE were updated in February 2006, January 2009 and Janauary 2011. Reference lists from trials selected by electronic searching were handsearched to identify further relevant trials. Published abstracts from conference proceedings from the United European Gastroenterology Week (published in Gut) and Digestive Disease Week (published in Gastroenterology) were handsearched. Members of the Cochrane UGPD Group, and experts in the field were contacted and asked to provide details of outstanding clinical trials and any relevant unpublished materials.

The Cochrane Highly Sensitive Search Strategy for identifying randomised trials in MEDLINE, Sensitivity maximising version, Ovid format (Higgins 2008), was combined with the search terms in Appendix 1 to identify randomised controlled trials in MEDINE. The MEDLINE search strategy was adapted for use in the other databases searched.

Searches were conducted to identify all published and unpublished randomised controlled trials. Articles published in any language were included.

\section{Searching other resources}

Reference lists from trials identified by electronic searching were handsearched to identify further relevant trials. Published abstracts of conference proceedings from the United European Gastroenterology Week and British Society of Gastroenterology (published in Gut) and Digestive Disease Week (published in Gastroenterology) were handsearched. The authors also handsearched conference abstracts from the World Congress of Gastroenterology, Digestive Disease Week of China and the International Gastric Cancer Congress.

In addition, members of the Cochrane UGPD Group and experts in the field were contacted and asked to provide details of outstanding clinical trials and any relevant unpublished materials.

\section{Data collection and analysis}

\section{Selection of studies}

All identified trials were reviewed to determine if they were RCTs or quasi-RCTs. The review of eligibility was carried out independently by three authors (YP Wang, C Bennett and T Pan). There was no difference in opinion. Trials published only in abstract form were included if full details of the protocol were given. Duplicate publications were excluded.

\section{Data extraction and management}

Studies were assessed for eligibility by T Pan, checked by YP Wang and independently assessed by $C$ Bennett. We did not identify any studies which met the inclusion criteria. If updated searches retrieve any reports of studies which meet the inclusion criteria for this review, they will be analysed using the methods detailed in Appendix 2.

\section{RES U LTS}

\section{Description of studies}

\section{Results of the search}

Electronic searches retrieved a total of 746 reports of studies from literature searches conducted in 2005, and updated in 2006, 2009 and 2011.

\section{Included studies}

No studies fitted the inclusion criteria.

\section{Excluded studies}

None of the reports of studies retrieved was suitable for inclusion. None of these excluded studies was an RCT; they were retrospective reviews of therapy for EGC, either single arm or controlled against other modalities of EMR or against surgery. There were only six studies which directly compared EMR with surgery (Mizumoto 1992; Nishida 1993; Fukase 1994; Tada 1998; Kim 2000; Fukase 2004). One further trial reviewed EMR and surgery cases retrospectively but this was not a direct comparison as it reported lymph node metastasis and mode of invasion in the EMR cases and background factors and treatment results in the surgery cases (Misumi 1991). Please see (Characteristics of excluded studies).

\section{Risk of bias in included studies}

There were no included studies.

\section{Effects of interventions}

There were no included studies.

\section{DISCUSSION}

Many studies of EMR have been published, particularly in the Japanese literature. There are currently no randomised controlled trials (RCTs) which evaluate the efficacy and safety of endoscopic mucosal resection (EMR) for early gastric cancer (EGC), or which compare EMR to gastrectomy for EGC. This discussion is, therefore, based on available evidence derived from reports of nonrandomised studies. It is difficult to draw conclusions from the data obtained from non RCTs as selection bias in the series quoted will be present.

\section{Indications for endoscopic mucosal resection}

Based on the Japanese classification of gastric carcinoma (Japanese GCA 1998), the indications for endoscopic therapy are (Tada 2000) as follows.

1. Well-differentiated adenocarcinoma. 
2. A tumour of size $20 \mathrm{~mm}$ or less in elevated types.

3. A tumour of size $10 \mathrm{~mm}$ or less in depressed types.

4. Not associated with peptic ulcer.

5. Invasion limited to the mucosa.

The incidence of lymph node metastasis from intramucosal EGCS fulfilling these criteria is small, reported as only $0.36 \%$ (Yamao 1996).

EMR can be used to completely resect small EGCs restricted to the mucosa or can be considered when the degree of invasion into the submucosa is minute (Noda 1997). In this review the participants' characteristics were predetermined by the characteristics of patients who were enrolled by the individual studies. Perhaps as a result of this, most of the trials we assessed only included people who had tumours with apparently limited local invasion and low risk of metastasis. The true depth of invasion is not normally known at the time of EMR and one of the advantages of EMR is that it provides detailed information on depth of invasion and risk of lymph node metastasis. If cases in which lesions were found to invade deeper than expected are excluded from studies, the potential advantage of EMR in such cases cannot be assessed. Some studies do report the application of EMR to patients with such expanded criteria (Kojima 1998). Kajiyama et al 1996 evaluated the diagnostic accuracy and therapeutic value of EMR for the treatment of sub-mucosal lesions in the gastrointestinal tract. In a series of 77 patients, they concluded that EMR can be used to eradicate some types of sub-mucosal lesions (Kajiyama 1996). In an assessment of local curability of early gastric cancer, that is, no recurrence of tumour in the stomach two years after treatment, patients who did not satisfy then current therapeutic indications were treated by EMR. These patients should have been treated by surgery but had severe concomitant disease. Local cure rate in these cases was only $67 \%$ compared with a $98 \%$ local cure rate for tumours that met the standard criteria (Amano 1998). Noda 1997 cautions that as surgical gastrectomy has a five-year survival rate of $98 \%$, any expansion of endoscopic therapy in EGC should at present only be in cases where there are clinical contraindications for surgical treatment. However, results from studies which support the use of EMR in patients having larger, well-differentiated mucosal carcinomas and developments in EMR techniques may influence widening the present indications for EMR. One report of long term outcomes for early gastric cancer patients treated with EMR that had completely removed tumours of less than $2 \mathrm{~cm}$ without ulcerative change. The overall diease specific 5 and 10 year survival rates were $99 \%$ and $99 \%$ retrospectively. The authors concluded that en bloc EMR ensured an excellent prognosis in patients with small differentiated mucosal early gastric cancers (Uedo 2006). Conversely, Kang 2010 et al conducted a review of review of 478 pathological specimens from participants who had undergone gastrectomy with lymph node dissection for the treatment of both mucosal and submucosal EGC. In that study, lymph node metastasis was demonstrated in some cases that appeared to meet established criteria for extended endoscopic submucosal dissection. Although the results may partly be explained by differences between pathologists in the diagnostic criteria and definition of EGC, the authors of Kang 2010 suggest that it may be necessary to re-evaluate whether the current literature, based on large Japanese datasets (for example Gotoda 2000), provides an accurate representation of the risk of LN metastasis in EGC lesions that apparently fall within current criteria for ESD of EGC.
Rabenstein 2008, reviewed the status of minimally invasive therapies for early gastric cancer outside Japan and stated that currently, these therapies should not be employed by inexperienced institutes outside of prospective studies.

\section{Resection rates}

Reported resection rates varied. In a review of 1832 cases in the Japanese literature, Kojima1998 reported that compete resection was achieved in $73.9 \%$ of cases (Kojima 1998). Higher rates have been reported: 90.4\% (Giovannini 1999), 97.7\% (Tani 1997) and Oizumi et al report only $9.7 \%$ residual lesions in patients with standard indications for EMR (Oizumi 1991). Lower rates of complete resection have been noted in series which expanded the indications for EMR (Hiki 1995). A large study, which prospectively recruited patients with early gastric cancer for treatment with EMR, gave an overall complete excision rate of $71.9 \%$ for patients who completed the study and had small, moderately to well-differentiated intramucosal carcinomas but only $46.3 \%$ for cases with larger differentiated carcinomas of size 2.1 to 4 $\mathrm{cm}$. Completeness of resection was assessed histopathologically and suitable incompletely resected cases underwent additional endoscopic treatment. Subsequent endoscopic findings, including biopsies, showed no residual tumour, indicating that in some cases of incomplete EMR repeat treatment can be successful in eliminating tumours (Ida 2004).

Factors which influence incomplete resection by EMR are probably related to the resection technique used, the definition of clear margins and the inclusion of patients with expanded criteria, for example patients who have tumours with some degree of submucosal invasion (Kojima 1998).

\section{Techniques}

Numerous types of and modifications to the technique of EMR have been described (Takeshita 1997b; Chonan 1998) and discussed in Tanabe et al (Tanabe 1999). Additionally, there is debate over single fragment or piecemeal resection with it being suggested that EMR for EGC be performed en bloc rather than by dividing the lesion (Miyata 2000; Ono 2001; Eguchi 2003). Resection rates are reduced in lesions that are difficult to remove as a result of their size or location on the anterior or posterior wall rather than the lesser curvature of the stomach (Takekoshi 1994). To ensure adequate resection, it is suggested that a 'security margin' of $2 \mathrm{~mm}$ between the edge of the resected specimen and the margin of cancer should be preserved (Mizumoto 1992; Hamada 1996).

\section{Residual and recurrent cancers}

Incomplete resection may result in persistence or reappearance of a tumour. Clinicians then need to explore the options of further endoscopic therapy, observation or surgery depending on the status and fitness of the patient for major surgery and the degree of invasiveness of the tumour (Kojima 1998). Tada 2000 discussed this and reported the development of a protocol to follow up incomplete resection.

Endoscopic re-treatment of recurrences after EMR can result in local cure. In one study the patients were followed up by endoscopic examination up to five years after the completion of initial treatment (and extended for a further three years after endoscopic re-treatment for recurrence). With respect to small, moderately to well-differentiated intramucosal carcinomas, in 
patients that completed the study "the long term results, including cases of additional treatment for residual cancer following the original EMR, showed that recurrence occurred in 8 out of 199 cases $(4.0 \%)$ in five of whom local cure was achieved with endoscopic treatment, giving a local final cure of $98.5 \% "$. The remaining three recurrent tumour patients, who underwent surgery, had no lymph node metastases (Ida 2004).

Local recurrence may occur in completely resected cases and may be explained by the inappropriate assessment of multi-fragment specimens (Ono 2001). In a large prospective study (Ida 2004), there were no cases of recurrence following complete excisions in a single procedure. The authors do, however, conclude that in the cases of incomplete resection there were still recurrences after additional treatments and that in order to achieve radical cure by EMR the lesion must be initially detected and treated at the stage of local intramucosal disease. Recently there have been reports that endoscopic submucosal dissection has the advantage of reducing the risk of local residual or recurrent tumour (Oda 2006) and that it is effective in treating locally recurrent tumours after conventional EMR (Yokoi 2006). These studies were both retrospective in design. Yokoi 2006 reported a retrospective uncontrolled series of patients who developed local recurrence of EGC after initial EMR treatment; these patients were then re-treated with ESD. The participants were treated with ESD rather than EMR as EMR causes local scarring of the submucosa whereas ESD through the fibrosis can resect the tumour en bloc, there were also three perforations in this small series of 46 patients.

A retrospective review of patients whose had been treated by EMR for early gastric cancer, suggested that the eradication of Helicobacter pylori "may help reduce the incidence of metachronous cancer" (Nagawa 2006). In an randomised controlled trial of patients who had undergone endoscopic mucosal resection (EMR) for early gastric cancer and who were treated with eradication of Helicobacter pylori, the incidence of metachronous gastric cancer in those participants who did not receive eradication therapy was significantly higher in control group (Fukase 2008).

Endoscopic monitoring may reveal the development of metachronous cancers, but the appropriate follow up interval has not yet been determined. Endoscopic surveillance of patients treated by EMR is recommended with suggested schedules of every six months for five years (Miyata 2000) or every three to six months for the first year and yearly thereafter (Kondo 2001). In order to detect metachronous lesions at an early enough stage for curative EMR, Nakajima 2006 suggested that endoscopic surveillance at one-year intervals was practical and effective.

\section{Complications and mortality due to endoscopic mucosal resection}

Mortality due to EMR is low. No cases were reported by Kojima 1998. Complications associated with EMR include bleeding and perforation (Nelson 2000). Bleeding and haemorrhage are managed by local coagulation therapy. Bleeding is more frequent when large lesions are removed or piecemeal resection techniques are employed (Noda 1997; Tanabe 1999). Rates of bleeding vary from $1.2 \%$ (Oizumi 1991) to $20.5 \%$ (Tanabe 1999) and are also described as 'frequent' (Ono 2001).
Perforation rates vary from $0.4 \%$ (Oizumi 1991) to $5.2 \%$ (Kondo 2001), this being managed by clipping or surgery. A multi-centre collaborative prospective study of endoscopic treatment of early gastric cancer reported haemorrhage rates of $1.7 \%$ (7/409) and only one case of perforation (0.2\%) (Ida 2004). Only one trial reported a comparison of complications of surgery compared with EMR. In a report comparing EMR with 256 radical surgery cases, postoperative complications occurred in $7.8 \%$ with an operative mortality of $0.78 \%$ in the radical surgery group. In the 56 EMR cases, nine experienced slight bleeding which was treated by ethanol injection using endoscopy (Mizumoto 1992). An RCT comparing preoperative PPI use with no pre-operative PPI use indicated that it is useful for controlling and preventing bleeding and that artifical ulcers created by EMR healed more quickly in participants who received preoperative PPIs (Watanabe 2006).

\section{Survival and long term outcomes}

Only one death after EMR was due to gastric cancer in the series reported by Kojima et al (Kojima 1998); with survival rates nearing $100 \%$ for small tumours with minimal submucosal invasion (Ponchon 2001). In a retrospective evaluation of endoscopic treatment (116 cases) for gastric cancer compared with surgical treatment (59 cases), survival rates with Kaplan-Meier curves were calculated. In patients who were younger than 65 years, five-year survival was $92.8 \%$ for EMR cases and $100 \%$ for surgery cases. The 10-year survival rates for patients less than 65 years of age were $92.8 \%$ for EMR treated cases and $91.7 \%$ for surgery cases. In patients older than 65 years of age, five-year survival was $80.8 \%$ for EMR treated cases and $100 \%$ for surgery cases. The 10 -year survival rates for patients older than 65 years of age were $80.8 \%$ for EMR and $75.0 \%$ for surgery cases. There were no significant differences between the results for patients older or younger than 65 or between the survival of EMR treated cases and surgically treated cases and this trend continued when the case were followed up after a further 10 years. (Fukase 1994; Fukase 2004). Similar rates were noted by (Kim 2000), that is two and five-year survival rates for EMR were $95 \%$ and $100 \%$ respectively and $100 \%$ and $100 \%$ respectively for surgically treated patients. Nishida et al (Nishida 1993) showed that in elderly patients (older than 75 years of age) endoscopic therapy showed better results than conventional surgery in the first two years and almost the same results after three years. Tada et al (Tada 1998, summarised in Tada 2000) looked at survival in 410 patients treated over a 15 -year period by strip EMR and 56 patients with the same types of lesion treated by surgery. Survival rates over five and ten years for EMR compared with surgery were $84.9 \%$ and $83.5 \%$ and $90.9 \%$ and $87.4 \%$ respectively, with no significant differences between the two groups.

\section{Quality of life (QoL)}

Only one study discussed quality of life. Takeshita 1997a referred to a report which indicated poor quality of life after gastrectomy. These authors suggested that QoL after EMR was favourable in terms of healing, diet, ability to work, drug therapy and performance status. Tada 1998 reported that "the therapy (EMR) is considered excellent from the viewpoint of quality of life".

\section{Cost}

A cost assessment was not included in the protocol for this review as it was considered to be outside the scope of a Cochrane review. In the trials assessed, no data regarding cost were reported. 
The EMR procedure requires a shorter hospital stay than surgical gastrectomy but the cost saving may be offset by the need for longterm endoscopic surveillance post EMR.

\section{AUTHORS' CONCLUSIONS}

\section{Implications for practice}

We found no evidence from RCTs to evaluate the safety and efficacy of endoscopic mucosal resection (EMR compared with gastrectomy for early gastric cancer (EGC). It is difficult to draw too many conclusions from the data obtained from non-RCTs as selection bias in the series quoted will be present.

As patients with EGC can expect a five-year survival of greater than $90 \%$ with surgical gastrectomy, and there are no prospective randomised controlled studies that evaluate the effectiveness of EMR compared with gastrectomy in EGC, it is difficult to assess if EMR should be adopted as the primary method of treatment for small EGCs. In terms of quality of life after treatment and its utility in patients who are unfit for surgery EMR does seem to be an attractive alternative (O'Mahony 2001). However, complications are not infrequent and there is a risk of incomplete resection or the development of recurrent or new cancers at a later date. Long-term regular endoscopic surveillance may be unacceptable to patients and would incur costs to the provider. Wide uptake of this technique in the West may require the provision of specialist centres with appropriately trained personnel. While EMR is the method of choice for early gastric cancer in Japan, in the West, for those institutions inexperienced in the diagnosis and therapy of gastrointestinal neoplasms, minimally invasive surgical procedures should be carried out on an individual basis or with the remit of a prospective study (Rabenstein 2008).

\section{Implications for research}

There is a wide variation in the range of results reported in published non-randomised studies, the reasons for this being unclear. A review of the different recurrence rates, metastasis rates and complication rates with the reasons for this variation is outside the scope of this review but if undertaken elsewhere could provide useful background information for practitioners and patients and may inform the design of properly controlled trials. It is recommended that future trials should analyse survival, employing Kaplan Meier curves and hazard ratios, this being a more powerful tool than assessment of survival at five and ten years only. Quality of life and cost effectiveness should also be investigated. The condition of patients and different modalities of EMR should be considered, if possible. Ideally, production of guidelines for the management of EGCs, including protocols for treatment of patients who are unsuitable for EMR or whose tumours are not completely resected, should be guided by results from properly designed controlled trials conducted by individuals who have had proper training in EMR.

\section{ACKNOWLEDGEMENTS}

We acknowledge the support and the invaluable help of the Cochrane Upper Gastrointestinal and Pancreatic Diseases Group in this review. 


\section{R E F E R E N C E S}

\section{References to studies excluded from this review}

Fukase 1994 \{published data only\}

Fukase K, Matsuda T, Suzuki M, Toda M, Okuyama Y, Sakai JI, et al. Evaluation of the efficacy of endoscopic treatment for gastric cancer considered in terms of long-term prognosis. A comparison with surgical treatment. Digestive Endoscopy 1994;6(3):241-7.

\section{Fukase 2004 \{published data only\}}

Fukase K, Kawata S. Evaluation of the efficacy of endoscopic treatment for early gastric cancer considered in terms of longterm prognosis more than 10 years - a comparison with surgical treatment [10年以上の長期予後成精からみた早期胃癌に 対ずる内視鐼的治療の評価一外枓的治療と比較して一]. Yamagata Medical Journal 2004;22(1):1-8.

Kim 2000 \{published data only\}

Kim H, Lee D, Baik S, Kim J, Kwon S, Kim D, et al. Endoscopic mucosal resection with a ligation device for early gastric cancer and precancerous lesions: comparison of its therapeutic efficacy with surgical resection. Yonsei Medical Journal 2000;41(5):577-83.

\section{Misumi 1991 \{published data only\}}

Misumi A, Mizumoto S, Misumi K, Harada K, Kako H, Honmyo U, et al. Indication and limitation of endoscopic surgery of early gastric cancer: an analysis of 290 early cancers operated on and 65 early cancers treated endoscopically [Endoscopic surgery $の$ 適応と限界: 韸験症の分杤と切除早期胃癌セなけるリソパ 鮕耺栘およぴ非運殑性侵癌の検討から]. Japanese Journal of Gastroenterological Surgery 1991;24(10):2610-4.

\section{Mizumoto 1992 \{published data only\}}

Mizumoto S, Misumi A, Harada K, Arima K, Hirata T, Yoshinaka I, et al. Evaluation of endoscopic mucosal resection (EMR) as a curative therapy against early gastric cancer [早期胃癌に対す る根治的療法としての内視鏡的粘膜切除術(EMR)の評価]. Nippon Geka Gakkai Zasshi 1992;93(9):1071-4.

Nishida 1993 \{published data only\}

Nishida T, Naruma K, Tanaka S, Inoue K, Teshima H, Yoshihara $\mathrm{M}$, et al. Comparison of endoscopic therapy and conventional surgery for treatment of early gastric cancer in elderly patients [高龄者早期胃癌セ衬する内視鏡的治療 法の検討一内視鏡的治療と外枓的治療の子後の比較一]. Nippon Romen lgakka Zasshi (Japanese Journal of Geriatrics) 1993;30(5):376-81.

\section{Tada 1998 \{published data only\}}

Tada M, Tanaka Y, Matsuo N, Shimamura T, Yanaguchi K. Mucosectomy for gastric cancer. Current status in Japan. Journal of Gastroenterology and Hepatology 2000;15(1):D98D102.

* Tada M, Tokiyama H, Nakamura H, Yania H, Okita K. Endoscopic resection for early gastric cancer. Acta Endoscopica 1998;28:87-95

\section{Additional references}

\section{Ahmad 2002}

Ahmad N, Kochman M, Long W, Furth E, Ginsberg G. Efficacy, safety and clinical outcomes of endoscopic mucosal resection: a study of 101 cases. Gastrointestinal Endoscopy 2002;55(3):390-6.

\section{Amano 1998}

Amano Y, Ishihare K, Amano K, Hirakiwa K, Adachi R, Fukuda M, et al. An assessment of local curability of endoscopic surgery in early gastric cancer without satisfaction of current therapeutic indications. Endoscopy 1998;30:548-52.

\section{Cancer Research UK 2007}

Cancer Research UK. UK Stomach Cancer incidence statistics (2007) (EU and Worldwide). http://info.cancerresearchuk.org/ cancerstats/types/stomach/incidence/\#geog (accessed 14 March 2011).

\section{Chonan 1998}

Chonan A, Mochizuki F, Ando M, Atsumi M, Mishima T, et al. Endoscopic mucosal resection of early gastric cancer usefulness of aspiration EMR using a cap fitted scope. Digestive Endoscopy 1998;10(1):31-6.

\section{DerSimonian 1986}

DerSimonian R, Laird N. Meta-analysis in clinical trials. Controlled Clinical Trials 1986;7:177-88.

\section{Eguchi 2003}

Eguchi T, Gotoda T, Oda I, Hamanaka H, Hasuike N, Saito D. Is endoscopic one-piece mucosal resection essential for early gastric cancer?. Digestive Endoscopy 2003;15:113-6.

\section{Fukase 2008}

K Fukase, M Kato, S Kikuchi, K Inoue, N Uemura. Effect of eradication of Helicobacter pylori on incidence of metachronous gastric carcinoma after endoscopic resection of early gastric cancer: an open-label, randomised controlled trial. The Lancet 2008;372(9636):392-7.

\section{Giovannini 1999}

Giovannini M, Berrardini D, Moutardier V, Moges G, Houvenaeghel G, Seitz JF, et al. Endoscopic mucosal resection (EMR): results and prognostic factors in 21 patients. Endoscopy 1999;31(9):698-701.

\section{Gotoda 2000}

Gotoda T, Yanagisawa A, Sasako M, Ono H, Nakanishi Y, Shimoda T, et al. Incidence of lymph node metastasis from early gastric cancer: estimation with a large number of cases at 2 centers. Gastric Cancer 2000;3(4):219-25.

\section{Hamada 1996}

Hamada T, Kondo K, Itagaki Y, Nishida J. Endoscopic mucosal resection for early gastric cancer. Nippon Rinsho (Japanese Journal of Clinical Medicine) 1996;54(5):1292-7. 


\section{Higgins 2008}

Higgins JPT, Green S, editors. Cochrane Handbook for Systematic Reviews of Interventions Version 5.0.0 [updated February 2008]. The Cochrane Collaboration, 2008. Available from www.cochrane-handbook.org.

\section{Hiki 1995}

Hiki Y, Shimao H, Mieno H, Sakakibara Y, Kobayashi N, Saigenji K. Modified treatment of early gastric cancer: evaluation of endoscopic treatment of early gastric cancer with respect to treatment indication groups. World Journal of Surgery 1995;19(4):517-22.

\section{Hiki 1996}

Hiki Y. Endoscopic mucosal resection (EMR) for early gastric cancer. Nippon Geka Gakkai Zasshi (Journal - Japan Surgical Society) 1996;97(4):273-8.

\section{Ida 2004}

Ida K, Nakazawa S, Yoshino J, Hiki Y, Akamatsu T, Asaki S, et al. Multicentre collaborative prospective study of endoscopic treatment for early gastric cancer. Digestive Endoscopy 2004;16:295-302.

\section{Inoue 2002}

Inoue H, Fukami N, T. Yoshida, Kuda S-E. Clinical and public health challenge of cancer endoscopic mucosal resection for esophageal and gastric cancer. Journal of Gastroenterology and Hepatology 2002;17(4):382-8.

\section{Japanese GCA 1998}

Japanese Gastric Cancer Association. Japanese Classification of Gastric Carcinoma - 2nd English edition. Gastric Cancer 1998;1(1):10-24.

\section{Kajiyama 1996}

Kajiyama T, Hajiro K, Saki M, Inoue K, Konishi Y, Takakuwa H, et al. Endoscopic resection of gastrointestinal submucosal lesions: a comparison between strip biopsy and aspiration lumpectomy. Gastrointestinal Endoscopy 1996;44(4):404-10.

\section{Kang 2010}

Kang HJ, Dae HK, Jeon TY, Lee SH, Shin N, Chae SH, et al. Lymph node metastasis from intestinal-type early gastric cancer:experience in a single institution and reassessment of the extended criteria for endoscopic submucosal dissection. Clinical Endoscopy 2010;72(3):508-15.

\section{Kashimura 1999}

Kashimura H, Ajioka Y, Watanabe H, Nishikura K, liri T, Asakura H. Factors for nodal micrometastasis of submucosal gastric carcinoma: Assessment of indications for endoscopic treatment. Gastric Cancer 1999;2(1):33-9.

\section{Kojima 1998}

Kojima T, Parra-Blanco A, Takahaski H, Fujita R. Outcome of endoscopic resection for early gastric cancer: review of the Japanese literature. Gastrointestinal Endoscopy 1998;48(5):550-5.

\section{Kondo 2001}

Kondo H, Gotoda T, Ono H, Oda I, Yamaguchi H, Saito D, et al. Early gastric cancer: endoscopic mucosal resection. Annali Italian di Chirugia 2001;72(1):27-31.

\section{Llorens 2000}

Llorens P, Pisano R, Pisano OR. Endoscopic mucosectomy in incipient gastric malignant lesions [Mucosectomia endoscopia en lesiones gastricas malignas incipientes]. Revista Medica de Chile 2000 Sep;128(9):969-76.

\section{Miyata 2000}

Miyata M, Yokoyama Y, Okoyama N, Joh K, Sasaki M, Ohara H, et al. What are the appropriate indications for endoscopic mucosal resection of early gastric cancer? Analysis of 256 endoscopically resected lesions. Endoscopy 2000;32(10):773-8.

\section{Nagawa 2006}

Nagawa S, Asaka M, Kata M, Nakamura T, Katao C, Fujioka T. Helicobacter pylori eradication and metachronous cancer after endoscopic mucosal resection of early gastric cancer. Alimentary Pharmacology and Therapeutics 2006;2(1):214-8.

\section{Nakajima 2006}

Nakajima T, Oda I, Gotoda T, Hamaka H, Eguchi T. Metachronous cancers after endoscopic resection: How effective is annual endoscopic surveillance?. Gastric Cancer 2006;9(2):93-8.

\section{Nelson 2000}

Nelson D, Block K, Bosco J, Burdick J, Curtis W, Faigel D, et al. Technology status evaluation report. Endoscopic mucosal resection. Gastrointestinal Endoscopy 2000;52(6):860-3.

\section{Noda 1997}

Noda M, Kodana T, Atsumi M, Nakajima M, Sawai N, Kashima K, et al. Possibilities and limitations of endoscopic resection for early gastric cancer. Endoscopy 1997;29(5):361-5.

\section{O'Mahony 2001}

O'Mahony, S. Endoscopic mucosal resection for early gastric cancer. Gut 2001;48(2):151-2.

\section{Oda 2006}

Oda I, Saito D, Tada M, lishi H, Tanabe S, Oyama T, et al. A multicenter retrospective study of endoscopic resection for early gastric cancer. Gastric Cancer 2006; Vol. 9, issue 4:262-70.

\section{Oizumi 1991}

Oizumi H, Matsuda T, Fukase K, Furasawa A, Mito S, Takahashi K. Endoscopic resection for early gastric cancer. The actual procedure and clinical evaluation. Stomach and Intestine 1991;26:289-300.

\section{Ono 2001}

Ono H, Kondo H, Gotoda T, Shirao K, Yamaguchi H, Saito D, et al. Endoscopic mucosal resection for treatment of early gastric cancer. Gut 2001;48(2):225-9.

\section{Parkin 2002}

Parkin DM, Bray F, Ferlay J, Pisani P. Global Cancer Statistics, 2002. CA: A Cancer Journal for Clinicians 2005;55(2):74-108. 


\section{Ponchon 2001}

Ponchon T. Endoscopic mucosal resection. Journal of Clinical Gastroenterology 2001;32(1):6-10.

\section{Rabenstein 2008}

Rabenstein T, Ell C, Feussner H. Endoscopic resection and minimally invasive procedures for gastric cancer. Onkologe 2008; Vol. 14, issue 4:350-61.

\section{Schlemper 2000}

Schlemper R, Riddell R, Kato Y, Borchard F, Cooper H, Dawsey S, et al. The Vienna classification of gastrointestinal epithelial neoplasia. Gut 2000;47(2):251-5.

\section{Suzuki 1999}

Suzuki Y, Hiraishi H, Kanke K, Watanabe H, Ueno N, Ishida M, et al. Treatment of gastric tumors by endoscopic mucosal resection with ligating device. Gastrointestinal Endoscopy 1999;49(2):192-8.

\section{Tada 2000}

Tada M, Tokiyama H, Nakamura H, Yania H, Okita K. Endoscopic resection for early gastric cancer [Résection endoscopique dans le cancer gastrique précoce]. Acta Endoscopica 1998;28(2):87-95.

\section{Takekoshi 1994}

Takekoshi T, Baba Y, Ota H, Kato Y, Yanigawa A, Tagaki K, et al. Endoscopic resection of early gastric carcinoma, a retrospective analysis of 308 cases. Endoscopy 1994;26(4):352-8.

\section{Takeshita 1997a}

Takeshita K, Tani M, Inoue H, Saeki I, Hayashi S, Honda T, et al. Endoscopic treatment for early oesophageal or gastric cancer. Gut 1997;40(1):123-7.

\section{Takeshita 1997b}

Takeshita K, Tani M, Inoue H, Saeki I, Honda T, Kando F, et al. Endoscopic treatment for early oesophageal or gastric cancer. Hepatogastroenterology 1997;44(18):1602-11.

\section{Tanabe 1999}

Tanabe S, Koizumi W, Kokutou M, Imaizumi H, Ishii K, Kida M, et al. Usefulness of endoscopic aspiration as compared with strip biopsy for the treatment of gastric mucosal cancer. Gastrointestinal Endoscopy 1999;50(6):819-2.

\section{Tani 1997}

Tani M, Takeshita K, Saeki I, Hayashi S, Honda T, Inoue H, et al. Protection of residue or recurrence following endoscopic mucosal resection for gastric tumorous lesions. Progress of Digestive Endoscopy 1997;50:74-8.

\section{Uedo 2006}

Uedo n, lishi H, Tatsuta M, Ishihara R, HIgashiro K, Takeguschi Y. Longterm outcomes after endoscopic mucosal resection for early gastric cancer. Gastric Cancer 2006;9(2):88-92.

\section{Watanabe 2006}

Watanabe Y, Kato N, Maehata T, Okamoto M, Tsuda T, Hattori S. Safer endoscopic gastric mucosal resection: preoperative proton pump inhibitor administration. Journal of Gastroenterology and Hepatology 2006;21(11):1675-80.

\section{Wehrmann 2001}

Wehrmann T, Lange P, Nakamura M, Riphaus A, Stergious N. Endoscopic mucosal resection of premalignant lesions of the upper gastrointestinal tract [Endoskopische mukosaresektion von (pra-)malignen veranderungen im oberen gastrointestinaltrakt]. Zeitschrift fur Gastroenterologie 2002;39(11):919-28.

\section{Yamao 1996}

Yamao T, Shirao K, Ono H, Kondo H, Saito D, Yamaguchi Y, et al. Risk factors for lymph node metastasis from intramucosal gastric carcinoma. Cancer 1996;77(4):597-8.

\section{Yokoi 2006}

Yokoi C, Gotoda T, Hamanaka H, Oda I. Endoscopic submucosal dissection allows curative resection of locally recurrent early gastric cancer after prior endoscopic mucosal resection. Gastrointestinal Endoscopy 2006; Vol. 48, issue 6:1259-66.

\section{Yoshikane 2001}

Yoshikane H, Sakakibara A, Hidano H, Niwa Y, Goto H, Yokoi Y. Piecemeal endoscopic aspiration mucosectomy for large superficial intramucosal tumors of the stomach. Endoscopy 2001;33(9):795-9.

\section{Zhou 1995}

Zhou L, Lin S, Ye S. Endoscopic mucosectomy for resection of early gastric cancer and precancerous lesions [內镜粘暯圢除 术切除胃內早期恶性病变]. Zhonhhua Nei Ke Za Zhi (Chinese Journal of Internal Medicine) 1995;34(7):443-5.

* Indicates the major publication for the study

CHARACTERISTICS OF STUDIES

Characteristics of excluded studies [ordered by study ID]

\begin{tabular}{ll}
\hline Study & Reason for exclusion \\
\hline Fukase 1994 & Non-randomised study (retrospective case review)
\end{tabular}




\begin{tabular}{ll}
\hline Study & Reason for exclusion \\
\hline Fukase 2004 & Non-randomised study (retrospective case review) \\
\hline Kim 2000 & Non-randomised study (retrospective case review) \\
\hline Misumi 1991 & Retrospective review of cases \\
\hline Mizumoto 1992 & Retrospective review of cases \\
\hline Nishida 1993 & Non-randomised study (retrospective case review) \\
\hline Tada 1998 & Non-randomised study (retrospective case review), reported in Tada 2000 \\
\hline
\end{tabular}

\section{APPENDICES}

\section{Appendix 1. MEDLINE search strategy}

1. randomized controlled trial.pt.

2. controlled clinical trial.pt.

3. randomized.ab.

4. placebo.ab.

5. drug therapy.fs.

6. randomly.ab.

7. trial.ab.

8. groups.ab.

9. 1 or 2 or 3 or 4 or 5 or 6 or 7 or 8

10. humans.sh.

11. 9 and 10

12. exp gastrectomy/

13. gastrectom\$.tw.

14. (gastr\$ adj10 resect\$).tw.

15. (stomach adj10 resect\$).tw.

16. or/12-15

17. (endoscop\$ adj5 mucosa $\$$ adj5 resect\$).tw.

18. (endoscop\$ adj3 mucosectom\$).tw.

19. or/17-18

20. 16 and 19

21. 11 and 20

22. limit 21 to $y r=" 2006-2009 "$ 


\section{Appendix 2. Methods to be used in future versions of the review}

\section{Data extraction and management}

Two authors will independently extract the data using a specially designed data extraction form. A third team member will resolve any differences in opinion. Two authors will independently check and enter the data into RevMan5.

\section{Assessment of risk of bias in included studies}

We shall describe each study in a 'Risk of bias' table, and address the following issues, which may be associated with biased estimates of treatment effect, that is, sequence generation, allocation sequence concealment, blinding, incomplete outcome data, selective outcome reporting and other potential sources of bias (Higgins 2008). We shall report specifically on:

(a) the method of generation of the randomisation sequence;

(b) the method of allocation concealment - it will be considered 'adequate' if the assignment could not be foreseen;

(c) who was blinded and not blinded (participants, clinicians, outcome assessors) if this is appropriate;

(d) how many participants were lost to follow up in each arm, and whether reasons for losses were adequately reported;

(e) whether all participants were analysed in the groups to which they were originally randomised (intention to treat principle).

In addition we may report on:

(f) the baseline assessment of the participants for age, sex, duration, location and stage of cancer

(h) whether outcome measures were described and their assessment was standardised;

(j) the use and appropriateness of statistical analyses, where tabulated data cannot be extracted from the original publication.

We shall record information on all these components in a 'Risk of bias' table. We shall also summarise the general quality of all the studies in the section on 'Risk of bias in the included studies'.

\section{Measures of treatment effect}

For studies of a similar type of radical endoscopic therapy (that is endoscopic therapy with curative intent) versus surgery, if sufficient trials are available and their populations are clinically similar, meta-analyses of primary and secondary end-points will be carried out.

For the time-to-event outcomes (survival), these outcomes may be reported as hazard ratio (HR) or log rank test and where these measures are provided in a trial report, they will be used.

For meta-analyses of dichotomous outcomes, relative risks (RR) or odds ratios (OR) will be calculated with 95\% confidence intervals (Cls) and combined for meta-analysis with RevMan5 software. Data will be combined for the same duration of follow up rounded to the nearest 6 months.

Continuous data will be combined for meta-analysis. We will use mean and standard deviations to derive a weighted mean difference (WMD) with $95 \%$ Cls using a fixed effect model.

\section{Unit of analysis issues}

We will seek input from the Cochrane Upper Gastrointestinal and Pancreatic Diseases Group editorial base for analysis issues involving any included trials with multiple treatment groups, and cluster randomised designs. We do not expect to identify any cross over trials as this design is inappropriate for this type of intervention, given that surgery and endoscopic therapies are intended to have a curative rather than temporary effect.

\section{Dealing with missing data}

We shall contact trial authors or sponsors of studies less than 10 years old to provide missing data. Where there is uncertainty about the specifics of a trial, we shall contact the trial authors for clarification.

\section{Assessment of heterogeneity}

Heterogeneity will be assessed with (12), which provides a measure of the degree of inconsistence in the studies' results with $95 \%$ uncertainty intervals (Higgins 2008). A value of $0 \%$ indicates no heterogeneity and a value greater than $50 \%$ is considered to be substantial heterogeneity.

\section{Assessment of reporting biases}

We shall test publication bias by the use of a funnel plot when adequate data are available for similar types of endoscopic therapies. If our analysis contains sufficient trials to make visual inspection of the plot meaningful (there is no standard for this, but we will assume that five trials is the minimum), and if the presence of asymmetry in the inverted funnel suggests a systematic difference between large and small trials in their estimates of treatment effect, we may comment on this in the Discussion section. 


\section{Data synthesis}

As a general rule, a fixed effect model will be used for calculations of summary estimates and their $95 \%$ Cls unless there is significant heterogeneity, in which case results will be confirmed using a random effects statistical model (DerSimonian 1986). We will compare relative risk of surviving in the endotherapy group compared with surgery at one or more years depending on the data available.

\section{Subgroup analysis and investigation of heterogeneity}

\section{Subgroup analysis}

We plan to perform subgroup analyses where adequate information is given in reports of studies. The groups will be different types of disease (mucosal cancer, submucosal cancer), and the age of participants as described by the trial authors. We may also consider subgroup analysis for types of endoscopic therapies or surgical techniques and on the basis of study design and reporting (adequate versus unclear allocation concealment for RCTs).

\section{Investigation of heterogeneity}

If substantial heterogeneity (12>50\%) exists between studies for the primary outcome, we shall explore the reasons for heterogeneity; such as age, cancer stage, histological type and treatment type. If it is inappropriate to pool the data because of clinical or statistical heterogeneity a systematic review without meta-analysis will be performed or a meta-analysis excluding outlying studies will be performed.

\section{Sensitivity analysis}

We plan to conduct sensitivity analyses to examine the effects of excluding studies defined as those with a moderate or high risk of bias as described in the Cochrane Handbook of Systematic Reviews of Interventions (Higgins 2008).

\section{Adverse outcomes}

We shall record:

1. the appropriateness of the methods used to detect adverse events;

2. the adequacy of reporting.

We shall describe the information qualitatively.

WHAT'S NEW

\begin{tabular}{lll}
\hline Date & Event & Description \\
\hline 1 October 2014 & Amended & Contact details updated. \\
\hline 18 April 2011 & Review declared as stable & Review declared stable as new evidence is unlikely. \\
\hline
\end{tabular}

\section{H I S T ORY}

Protocol first published: Issue 3, 2003

Review first published: Issue 1, 2006

\begin{tabular}{lll}
\hline Date & Event & Description \\
\hline 27 March 2011 & New search has been performed & $\begin{array}{l}\text { Updated with new search results and minor text edits, no new in- } \\
\text { cluded studies, no other changes. }\end{array}$ \\
\hline 20 September 2010 & Amended & Contact details updated. \\
\hline 10 May 2010 & Amended & Contact details updated \\
\hline 28 June 2009 & $\begin{array}{l}\text { New citation required but conclusions } \\
\text { have not changed }\end{array}$ & Updated, no new studies included \\
\hline \hline
\end{tabular}




\begin{tabular}{lll}
\hline Date & Event & Description \\
\hline 18 April 2006 & Amended & Minor update, converted to new format. \\
\hline
\end{tabular}

\section{CONTRIBUTIONS OF AUTHORS}

YP Wang conceived the topic and designed the review.

C Bennett, YP Wang and T Pan, screened the papers against inclusion criteria, appraised the quality of the papers and extracted data from the papers.

C Bennett and YP Wang wrote the review.

C Bennett updated the review (February 2006, June 2009, March 2011)

\section{DECLARATIONS OF INTEREST}

None known

\section{SOURCES OF SUPPORT}

\section{Internal sources}

- Chinese Cochrane Center, Chinese Center of Evidence-based Medicine, West China Hospital of Sichuan University, China.

\section{External sources}

- China Medical Board of New York (Grant number 98-680), China.

\section{INDEX TERMS}

\section{Medical Subject Headings (MeSH)}

Gastrectomy; Gastric Mucosa [ ${ }^{\star}$ surgery]; Gastroscopy [adverse effects] [ ${ }^{\star}$ methods]; Stomach Neoplasms [pathology] [ ${ }^{\star}$ surgery]

\section{MeSH check words}

Humans 